\title{
Efeito Antibacteriano de Linhagens de Saccharomyces cerevisiae Contra Klebsiella pneumoniae e Staphylococcus aureus
}

Leonardo Matheus Pereira Aguiar (I), Viviane Maia da Silva (I), Suzana Ferreira Magalhães-Gadéa (I), Ana Paula Trovatti Uetanabaro (II)

(I) UEFS - Universidade Estadual de Feira de Santana (Avenida Transnordestina, $\mathrm{s} / \mathrm{n}$, Novo Horizonte-Feira de Santana, BA.), (II) UESC - Universidade Estadual de Santa Cruz (Rodovia Jorge Amado,s/n,Salobrinho-Ilhéus, BA)

\section{Resumo}

Vários micro-organismos, dentre os quais se destacam bactérias e fungos detêm a capacidade de produzir metabólitos capazes de inibir os processos vitais de outros micro-organismos em seu habitat natural ou in vitro. $\mathrm{O}$ desenvolvimento de pesquisas atreladas a ação antagônicas desses organismos contra agentes patogênicos mostrou-se altamente efetiva e produtiva ao longo do tempo, tendo como resultado, o desenvolvimento de produtos antimicrobianos para as áreas industriais e médicas. Desta forma, o presente trabalho tem como objetivo avaliar os efeitos antibacterianos de 47 linhagens de Saccharomyces cerevisiae, isoladas em fermentações espontâneas da produção de cachaça artesanal, depositadas na Coleção de Cultura de Micro-organismos da Bahia (CCMB), contra as bactérias Klebsiella pneumoniae ATCC13883 e Staphylococcus aureus ATCC12600. $\mathrm{O}$ teste in vitro para verificar a produção de substâncias inibitórias difusíveis foi realizado pelo método da dupla camada. Uma alíquota de 5 $\mu \mathrm{L}$ da cultura da levedura crescida em caldo Yeast Peptone Glucose (YPG) durante 24 horas, a $37^{\circ} \mathrm{C}$, foi alocada no centro da placa de petri contendo ágar Sabouraud Dextrose. Após incubação a $37^{\circ} \mathrm{C}$, por 48 horas, estas foram colocadas em posição invertida e em cada tampa foi adicionado 1 $\mathrm{mL}$ de clorofórmio (100\%). Depois de 30 minutos, foram abertas para evaporação do clorofórmio residual em capela de exaustão e uma

\footnotetext{
Referência:

Leonardo Matheus Pereira Aguiar, Viviane Maia da Silva, Suzana Ferreira Magalhães-Gadéa, Ana Paula Trovatti Uetanabaro. Efeito Antibacteriano de Linhagens de Saccharomyces cerevisiae Contra Klebsiella pneumoniae e Staphylococcus aureus. In: Anais do 12 Congresso Latinoamericano de Microbiologia e Higiene de Alimentos MICROAL 2014 [= Blucher Food Science Proceedings, num.1, vol.1]. São Paulo: Editora Blucher, 2014. DOI 10.5151/foodsci-microal-316
} 
sobrecamada de 3,5 mL de ágar Brain Heart Infusion (BHI) semi-sólido ( $0,7 \%$ de ágar) acrescido de $10 \mu \mathrm{L}$ de uma cultura da bactéria reveladora, crescida por 24 horas a $37^{\circ} \mathrm{C}$ em caldo $\mathrm{BHI}$, foi colocada sobre o ágar. Após incubação a $37^{\circ} \mathrm{C}$ por 24 horas, efetuou-se a leitura de possíveis halos de inibição. O critério de determinação dos resultados foi a presença ou ausência do halo de inibição, independente da sua dimensão. Todos os testes foram realizados em triplicatas. Das 47 amostras, 06 apresentaram formação de halo contra Klebsiella pneumoniae e 25 apresentaram contra S. aureus. Os resultados obtidos por meio destes testes, evidenciam a viabilidade da utilização de algumas linhagens de Saccharomyces cerevisiae como possíveis agentes antibacterianos.

Palavras-Chave: Antimicrobiano, Saccharomyces cerevisiae, Bactérias Agência de Fomento: 